\title{
The multifaceted role of ischemia/reperfusion in sickle cell anemia
}

\author{
Robert P. Hebbel, John D. Belcher, and Gregory M. Vercellotti \\ Division of Hematology-Oncology-Transplantation, Department of Medicine and Vascular Biology Center, University of Minnesota Medical School, Minneapolis, Minnesota, USA.
}

\begin{abstract}
Sickle cell anemia is a unique disease dominated by hemolytic anemia and vaso-occlusive events. The latter trigger a version of ischemia/reperfusion (I/R) pathobiology that is singular in its origin, cyclicity, complexity, instability, perpetuity, and breadth of clinical consequences. Specific clinical features are probably attributable to local I/R injury (e.g., stroke syndromes) or remote organ injury (e.g., acute chest syndrome) or the systematization of inflammation (e.g., multifocal arteriopathy). Indeed, by fashioning an underlying template of endothelial dysfunction and vulnerability, the robust inflammatory systematization no doubt contributes to all sickle pathology. In this Review, we highlight I/R-targeting therapeutics shown to improve microvascular blood flow in sickle transgenic mice undergoing I/R, and we suggest how such insights might be translated into human therapeutic strategies.
\end{abstract}

The sickle mutation in the $H B B$ gene encoding $\beta$ globin results in formation of sickle hemoglobin (HbS) rather than normal HbA. When homozygous, this causes sickle cell anemia (SCA), a unique disease characterized by hemolytic anemia, recurrent vascular occlusions, a systemic inflammatory state, substantial multiorgan disease, foreshortened lifespan, and much suffering. All this stems from the abnormal behaviors of HbS: deoxygenated HbS assembles reversibly into rigid polymers (1), and oxygenated $\mathrm{HbS}$ is modestly unstable (2). While the former dominates the disease, the latter does foster development of pathogenic red blood cell $(\mathrm{RBC})$ membrane abnormalities, as reviewed elsewhere $(3,4)$.

Vaso-occlusions punctuate the clinical course with severe acute painful episodes that are unpredictable in occurrence and variable in frequency. Despite its prominence, sickle vaso-occlusion still presents abundant mysteries that have prompted counterpoised queries (5): "Why don't vaso-occlusions occur all the time?" versus "Why do vaso-occlusions occur at all?" The answer to both questions, we believe, is that SCA is a disease powered by ischemia/reperfusion (I/R) injury pathobiology, a conclusion grounded in data from sickle transgenic mice, SCA patients, and the general I/R literature. In particular, I/R pathophysiology underlies the unique inflammatory context of SCA, a state that is cyclic, systemic, intense, complex, unstable, and perpetual. Thus, we regard I/R as the modern formulation of the "vicious cycle" between erythrostasis and occlusion presciently posited by Ham and Castle in 1942 (Figure 1).

In this Review, we briefly describe the concept of I/R injury and then emphasize the I/R features of the sickle context that

Conflict of interest: RPH is a Scientific Advisory Board member for Emmaus Life Sciences and has a minor equity interest in Vanguard Therapeutics. JDB and GMV are consultants for and receive research funding from Hillhurst Biopharmaceuticals, CSL Behring, and Mitobridge/Astellas.

Copyright: () 2020, American Society for Clinical Investigation.

Reference information: J Clin Invest. 2020;130(3):1062-1072.

https://doi.org/10.1172/JCl133639. match classical I/R models and diseases. We then link these features to the vascular wall pathobiology of SCA and thence to specific clinical features. We conclude by commenting on therapeutic implications and opportunities.

\section{I/R in general}

At its core, $\mathrm{I} / \mathrm{R}$ is the pathobiology of resolving ischemia - tissue injury not only derives from ischemia but also is paradoxically exacerbated by reperfusion-enabled reentry of oxygen (6-8). This pathobiology is an integral part of human diseases such as stroke, myocardial infarction, organ transplantation, bowel ischemia, acute renal injury, trauma, limb ischemia, postpriapic erectile tissue damage, and SCA (8). Predictably, I/ $\mathrm{R}$ is a risk of therapeutic revascularization procedures.

In some respects, SCA mirrors the I/R of other diseases, but in other respects it differs substantially. To elucidate sickle I/R pathobiology, we here parse it into a stepwise pathogenic vector: (a) a triggering vascular event, (b) development of local I/R injury, (c) systematization of inflammation, (d) development of vascular wall disease, and (e) clinical consequences. A caution, however: SCA and I/R each involve vastly complex, intricately interactive, and temporally/locationally variable systems biologies. Neither can be reviewed thoroughly in the present context. So, this Review emphasizes the overlapping aspects of the two pathobiologies.

\section{The occlusive trigger in SCA}

In classical I/ $\mathrm{R}$ diseases, a triggering vascular occlusion typically involves an artery, but in SCA, the occlusions are microvascular events. A long-held assumption was that this results from $\mathrm{HbS}$ polymerization instigating $\mathrm{RBC}$ rigidification and shape change ("sickling"). However, for most sickle RBCs to undergo this calamitous transformation, something must slow their microvascular transit, i.e., provide sufficient time for polymer to form $(1,9)$.

The basis for such slowing is understood to be the abnormal adhesion of blood cells to microvascular endothelium, with most data pertaining to sickle RBCs (10-13) and/or leukocytes $(14,15)$. 


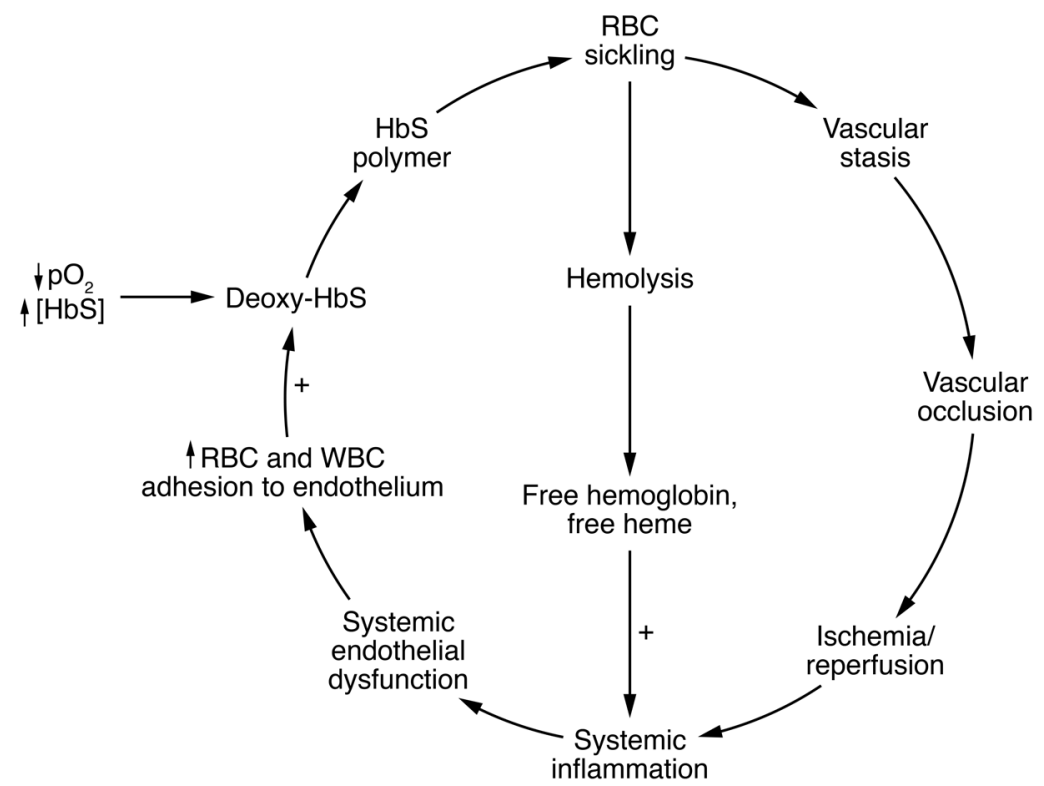

Figure 1. The pathophysiology of sickle cell anemia is cyclic, with a robust inflammatory state that is driven by blood cell adhesion to endothelium, leading to I/R. available, with sickle-like phenotypes ranging from mild to severe.

At their unmanipulated baseline, such mice exhibit many aberrances, including: abnormal blood cell activation, oxidant generation, elaboration of inflammatory mediators, and coagulation activation; endothelial cell dysfunction; growth factor imbalances; tissue hypoxia; and organ pathologies. Although parallel data on SCA patients are vexingly unsystematic, they clearly confirm that these murine aberrances also are features of human SCA. This reflects the centrality of systemic inflammation.

Additional insight derives from sickle mice transiently provoked by exposure to modest hypoxia (7\%-11\% $\mathrm{O}_{2}$ for $1-4$ hours), followed by reoxygenation via return to room air, with endpoints monitored anywhere from 5 minutes to 24 hours thereafter (18). This provocation, termed $\mathrm{H} / \mathrm{R}$, is intended to instigate transient RBC sickling and occlusion(s), followed by resolution. In normal mice, such $\mathrm{H} / \mathrm{R}$ provocation causes little change, but in sickle mice it induces unmistakable I/R pathobiology.
In sickle transgenic mice, such adhesion in postcapillary venules causes sluggish flow, sometimes outright blockage, with retrograde RBC sickling observed as a secondary event $(12,13)$. The adhesion biology of this is addressed in a later section. Heterocellular interactions, platelets, and neutrophil extracellular traps can contribute to occlusion as well $(15,16)$.

\section{Ischemia and local I/R injury}

Notwithstanding its unique initiation, the evolution of ischemia in SCA no doubt matches that in other diseases and experimental I/R models: a progression beginning with rundown of ATP and culminating in mitochondrial failure (8). The pathobiology of I/R injury lies in between the extremes of full tissue recovery (from early restoration of blood flow) and tissue death from reperfusion failure. During this phase, conversion of xanthine oxidoreductase to xanthine oxidase (XO) begins (17).

In large-vessel $\mathrm{I} / \mathrm{R}$ diseases, the severity of local $\mathrm{I} / \mathrm{R}$ injury depends on extent and duration of the ischemia, although susceptibility varies by organ and cell type (8). As a microvascular disease, SCA also must derive severity from occlusive multifocality, perhaps - but not necessarily - requiring stochastic locational convergence for actual I/R injury to occur. Occlusive events occur recurrently - and, we suspect, incessantly, propelling the perpetuity of the sickle inflammatory state.

I/R impact can also be influenced by genetics, epigenetics, differential organ susceptibilities, and the microbiome, as reviewed elsewhere (8). SCA additionally involves some fundamental vulnerabilities. Before discussing the $\mathrm{I} / \mathrm{R}$ reperfusion phase and its sequelae, we describe the instructive experimental sickle models.

\section{Sickle transgenic mouse models}

Much insight is provided by sickle transgenic mice in which human $\alpha$ - and $\beta^{\text {s}}$-globin genes have been added or swapped in for murine globin genes. Several such sickle mouse models have been

\section{Reperfusion and local injury}

Reoxygenation of the ischemic area causes local I/R Injury, the defining feature of $\mathrm{I} / \mathrm{R}$ pathobiology. The early footprints of this in non-sickle I/R injury models $(7,8)$ are also evident in $\mathrm{H} / \mathrm{R}-$ provoked sickle mice, as follows:

Newly formed $\mathrm{XO}$ uses xanthine and oxygen to generate superoxide $\left(\mathrm{O}_{2}^{-}\right)$, and XO layers onto distant endothelium $(17,19)$. Generation of $\mathrm{O}_{2}^{-}$and $\mathrm{H}_{2} \mathrm{O}_{2}$ is boosted, including within endothelium, and hydroxyl radical is generated $(17,19,20)$. NF-kB activation ensues in endothelium, blood cells, and tissues (17, 21-24). Complement is activated and deposited on cells and tissues (25). Blood quickly acquires inflammation promoters, e.g., TNF, IL-1 $\beta$, HMGB1 (26-28). RBCs disgorge HbS, mimicking the hyperhemolysis of acute vaso-occlusive episodes in SCA (29). Leukocytes become locally activated $(27,30)$, releasing cytokines and chemokines, as do tissue mast cells (31).

In due course, the sickle mice develop additional aberrances. Endothelial cells become activated, as evidenced by increased expression of P-selectin, VCAM-1, and tissue factor (Figure 2), appearing at time scales of minutes, 4 to 8 hours, and 12 to 18 hours, respectively $(14,18,21,22,27)$. Convincingly, H/R provocation of mild-phenotype sickle mice converts their nearly normal endothelium to an activated one resembling that of unprovoked severe-phenotype sickle mice (18). P-selectin-dependent leukoadhesion to microvascular endothelium greatly increases, and leukocyte emigration ensues (14). Occlusive events and microinfarcts develop in the brain $(32,33)$, and more obvious damage appears in the liver and kidney $(23,34)$. Even without $H / R$ provocation, severe-phenotype sickle mice exhibit substantial pathology such as infarctions in liver, kidney, spleen, and brain (35).

\section{Therapeutic corroboration}

That these footprints of I/R injury are actually involved in sickle pathogenesis is confirmed by corresponding therapeutic inter- 


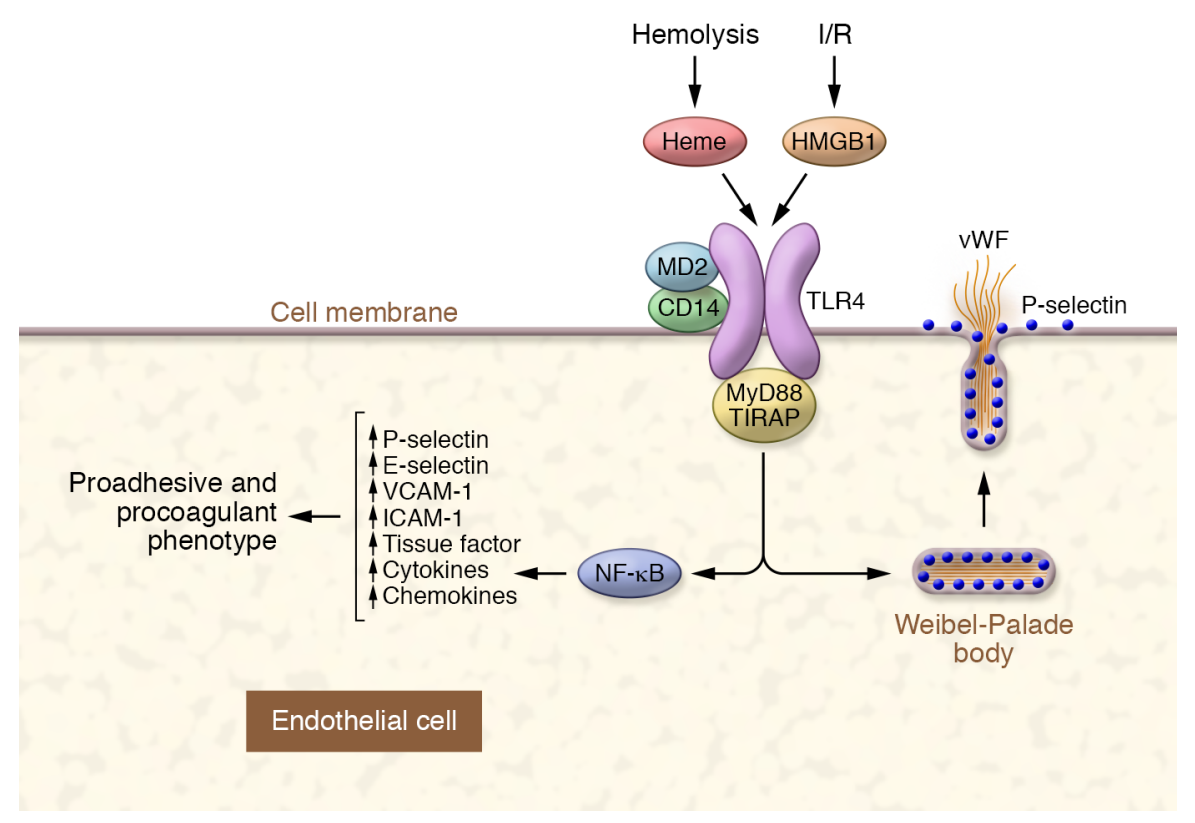

Figure 2. Biological convergence of heme and HMGB1 as inflammatory instigators. Activation of TLR4 leads to the secretion of Weibel-Palade bodies as well as proadhesive and procoagulant phenotypes in vascular endothelial cells.

ventions. Many strategies and agents are shown to exert vascular endothelial benefit in $\mathrm{H} / \mathrm{R}$-provoked sickle mice $(36,37)$. Among these strategies, we emphasize those shown to actually improve microvascular blood flow: (a) oxidant suppression using allopurinol to inhibit XO (17), superoxide dismutase (20), catalase (20), polynitroxyl albumin (38), or functional deficiency of NADPH oxidase (39); (b) NF- $\mathrm{BB}$ inhibition using sulfasalazine (20), $\mathrm{p}^{-/-}$ $(24,27)$, dexamethasone $(22)$, and the hydroxamic acid derivatives didox and trimidox (40); (c) inflammatory blunting using etanercept to block TNF (27), TAK-242 to inhibit TLR4 signaling (26), and antibodies against C5 or C5aR to impede complement (25); (d) application of endothelial-sparing agents such as lovastatin (18), the histone deacetylase inhibitor trichostatin A (41), haptoglobin and hemopexin (42), and added heme oxygenase-1 (43) or CO $(44,45)$; and (e) antiadhesive strategies such as heparinoids (46), 2-fluorfucose (47), blockade of P-selectin in cremaster (14), cerebral (48), and dermal vessels (26), and blockade of VCAM-1 or ICAM-1 in dermis (26). This spectrum of effective strategies and agents in $\mathrm{H} / \mathrm{R}$-provoked sickle mice is consistent with the understanding of I/R injury generally $(6,7,8,49)$.

\section{Perfusion paradox}

Postischemic reperfusion can spread locally activated leukocytes such that they plug nearby capillaries, creating a "no reflow" area that expands the local I/R injury (8). This can instigate a "perfusion paradox" whereby macrovascular hyperperfusion and microvascular hypoperfusion exist concurrently, e.g., as documented in sickle mouse brain (50) and kidney, (34) as well as in the brain in SCA patients $(51,52)$.

\section{Systematization of inflammation}

In $\mathrm{I} / \mathrm{R}$ diseases, reperfusion can disperse inflammatory influences beyond the initial injury area, thus bathing endothelium throughout the vascular tree. In severe cases, such as SCA, the resulting systemic inflammation intensifies and arborizes as additional mal- adaptive changes are recruited and the amount of affected endothelium extends. Homeostasis becomes increasingly compromised as the milieu gains complexity. This state is thoroughly evident in unmanipulated sickle mice at their baseline and in SCA patients. Some of its prominent features are as follows.

\section{Cyclicity and perpetuity}

In the specific sickle context, this systematization step fosters development of an inflammatory and adhesive endothelium that captures blood cells, leading to microvascular occlusion (12-14). Thus, occlusion causes adhesion causes occlusion, potentially ad infinitum. For this reason, we believe that the unique I/R-driven cyclicity is the governing instigator of the sickle inflammatory state (Figure 1).

In SCA, I/R events are recurrent - and probably incessant. Evidence for the latter is provided by SCA individuals with a very mild disease history, who are wholly asymptomatic and far remote from acute events, but still exhibit chaotic fluctuations of inflammatory biomarkers, as illustrated elsewhere (53). Absent symptoms, this identifies an underlying unsteadiness and/or intermittency. Yet, during such periods, patient hemolysis appears steady. Our interpretation, therefore, is that the so-called SCA "steady state" between acute events is actually a period when occlusions continue to occur, but are of insufficient magnitude to trigger clinical awareness.

Consequently, thought has generally focused on recurrent incitement as a defining feature of sickle inflammation. Recently, however, data from sickle mice have suggested that pathophysiology may additionally involve a failure of normal inflammation resolution mechanisms (54). If so, SCA shares this with other chronic inflammatory diseases, e.g., rheumatoid arthritis.

\section{Inducers of sterile inflammation}

It has become evident that damage-associated molecular patterns (DAMPs) (55) that are sterile inflammation-inducing, TLR4-signaling ligands may well be dominant instigators in SCA. For exam- 


\section{Table 1. Clinical disease features likely involving I/R pathobiology in sickle cell anemia}

\begin{tabular}{|l}
\hline Local I/R injury \\
Stroke (silent, clinical, hemorrhagic transformation) \\
\hline Cognitive deficits \\
\hline Kidney disease \\
\hline Bone pain \\
\hline Abdominal pain \\
\hline Postpriapic erectile dysfunction \\
\hline Nociceptive hypersensitivity \\
\hline Retinopathy \\
\hline Liver disease \\
\hline Perfusion paradox \\
\hline Remote organ injury \\
\hline Acute chest syndrome \\
Systematization of inflammation \\
All of the above \\
Endothelial dysfunction \\
Arterial vasculopathy \\
\hline
\end{tabular}

ple, H/R-provoked sickle mice develop increased plasma HMGB1 (28) and hemoglobin/heme (26). In SCA patients, both are elevated at baseline and both increase further in association with acute vaso-occlusive events $(28,29)$. Interestingly, there can be TLR4 signaling synergy between HMGB1 and either hemoglobin or heme (28). We hypothesize that heparan sulfate (56), released by inflammatory glycocalyx degradation, plays a similar role. Inhibition of DAMP signaling via TLR4 knockout improves microvascular flow in H/R-provoked sickle mice (26).

\section{Unusual vulnerabilities in SCA}

\section{Endothelial dysfunction}

Sickle mice $(57)$ and SCA patients $(58,59)$ exhibit persistent endothelial dysfunction, itself a hallmark feature of I/R. This must bestow exquisite vulnerability on the vascular wall with regard to impact of any new insult. A suggestive example from a non-sickle study revealed that when endothelial nitric oxide synthase (eNOS) is deficient, the pulmonary vasoconstrictive effect of hypoxia is greatly magnified (60); this is of concern in sickle sleep apnea (61).

\section{DAMPs}

By activating the NLRP3 inflammasome, DAMPs can create a primed state in endothelial cells, monocytes, and platelets - in essence, this represents a "hair trigger" for subsequent release of IL-1 $\beta$ and HMGB1 (62-64). Opportunity for pathogenic synergy is presented by the superimposed, high expression of TLR4 in sickle monocytes (65). Such leukocyte activation can result from their activating interaction with sickle $\operatorname{RBCs}(66,67)$, and we suspect the same is true of endothelial cells because of the injury response they manifest in response to sickle $\operatorname{RBCs}(68,69)$.

\section{Genetics}

Polymorphisms in non-globin genes can modulate I/R impact (8). Suggesting this, the Duffy-null state highly prevalent in sub-Saha- ran Africa bestows increased severity in cases of acute lung injury (70), a classical complication of SCA. Another example is a TLR4 polymorphic haplotype, prevalent only in sub-Saharan Africa, that augments inflammatory signaling by TLR4 ligands (71).

\section{Conditioning and concurrency}

Remarkably, a facet of I/R injury generally is that mild ischemia, insufficient to induce injury, can actually exert a "conditioning" effect that can ameliorate a subsequent I/R injury, even at a distant location (8). So, it seems highly likely that at any given time, the milieu of an SCA patient is an unpredictable mixture of effects from new I/R injuries plus resolving I/ $\mathrm{R}$ injuries plus conditioning effects from mild events. We suggest that this ever-changing milieu contributes to the characteristic instability of the sickle inflammatory state. Whether conditioning can be exploited for benefit in SCA deserves clinical investigation. A hint of support lies in a demonstration that exercise training of sickle mice reduces their systemic inflammation (72).

\section{Hemolysis and its products}

Kato et al. have described SCA patients as being either hemolytic or vaso-occlusive in phenotype (73). However, the I/R and hemolytic components of SCA are inextricably linked. Both derive from HbS polymerization and RBC sickling, and the DAMPs produced by the two processes (HMGB1 and heme) biologically converge at TLR4 signaling (Figure 2). Thus, our view is that the two processes are codominant, each contributing to every clinical feature.

Not surprisingly, therefore, it has thus far been impossible to meaningfully parse out the proportionate contributions of hemolysis and I/R. However, two new sickle pharmaceuticals perhaps could be experimentally exploited to do so. Crizanlizumab blocks P-selectin-mediated adhesion biology; it blunts vaso-occlusive severity but has no effect on hemolysis (74). Conversely, voxelotor locks HbS molecules into the oxyHb configuration; it reduces hemolysis but has no effect on vasoocclusive severity (75).

Intravascular hemolysis exposes multiple harmful perturbants (4). Cell-free oxyHbS consumes NO in extracellular space (76). Released RBC microparticles (77) can activate monocytes, damage endothelium $(78,79)$, and enhance thrombin generation (80). Released arginase can depress plasma L-arginine. Cellfree oxyHbS quickly auto-oxidizes to release free heme (2) that avidly enters and oxidizes plasma low-density lipoproteins (81); heme similarly enters endothelial membranes, exerting injurious inflammatory effects (82). That this is relevant is suggested by the ameliorative effect of an apolipoprotein A mimetic in sickle mice (83). Indeed, our data suggest that one-half of heme's inflammatory impact on endothelium is TLR4-independent.

\section{Vascular wall: the interface between biology and pathology}

The vascular wall bears the brunt of I/R-driven inflammation, with endothelium being its pivotal pathobiologic target. This is critical because normal vascular health requires successful endothelial integration of myriad inputs to organize adaptive homeostatic responses. In doing so, it adaptively links different biophysiologic functions, e.g., inflammation, coagulation, vasoregulation, 
A
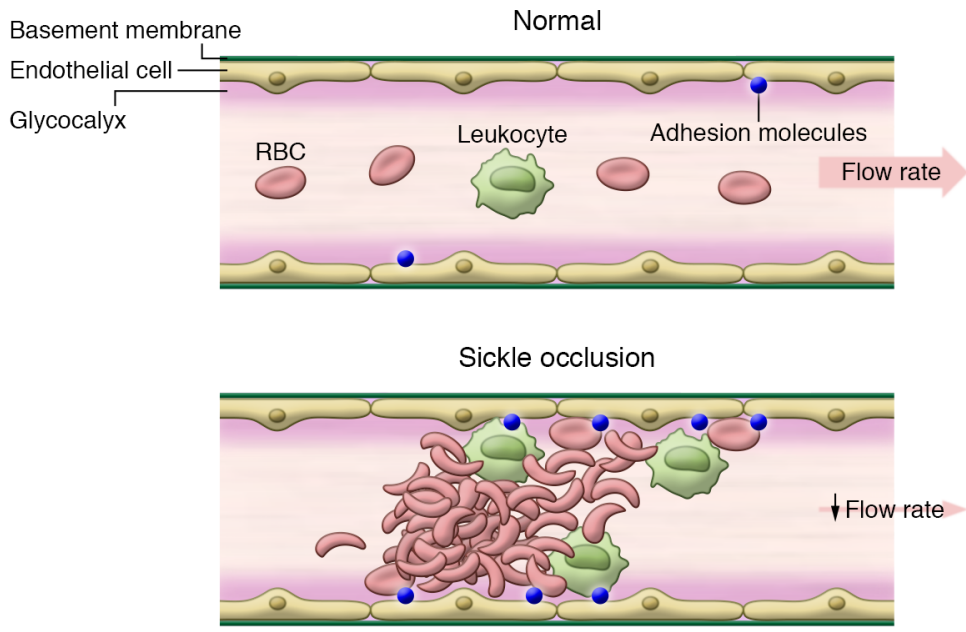

Sickle baseline

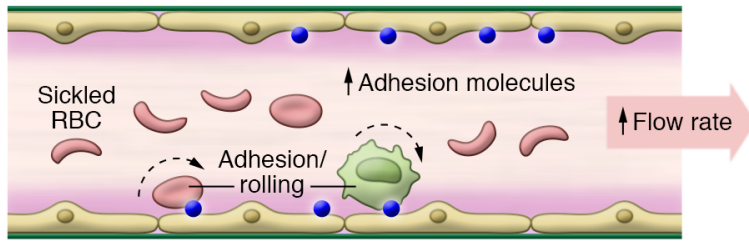

Reperfusion

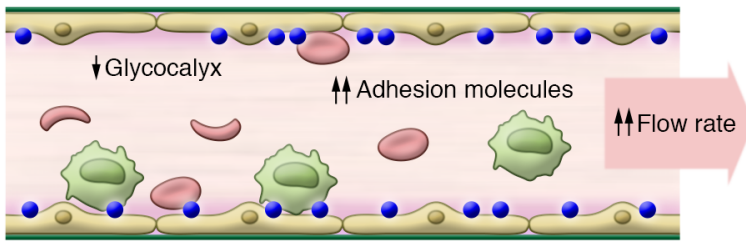

B

Reperfusion

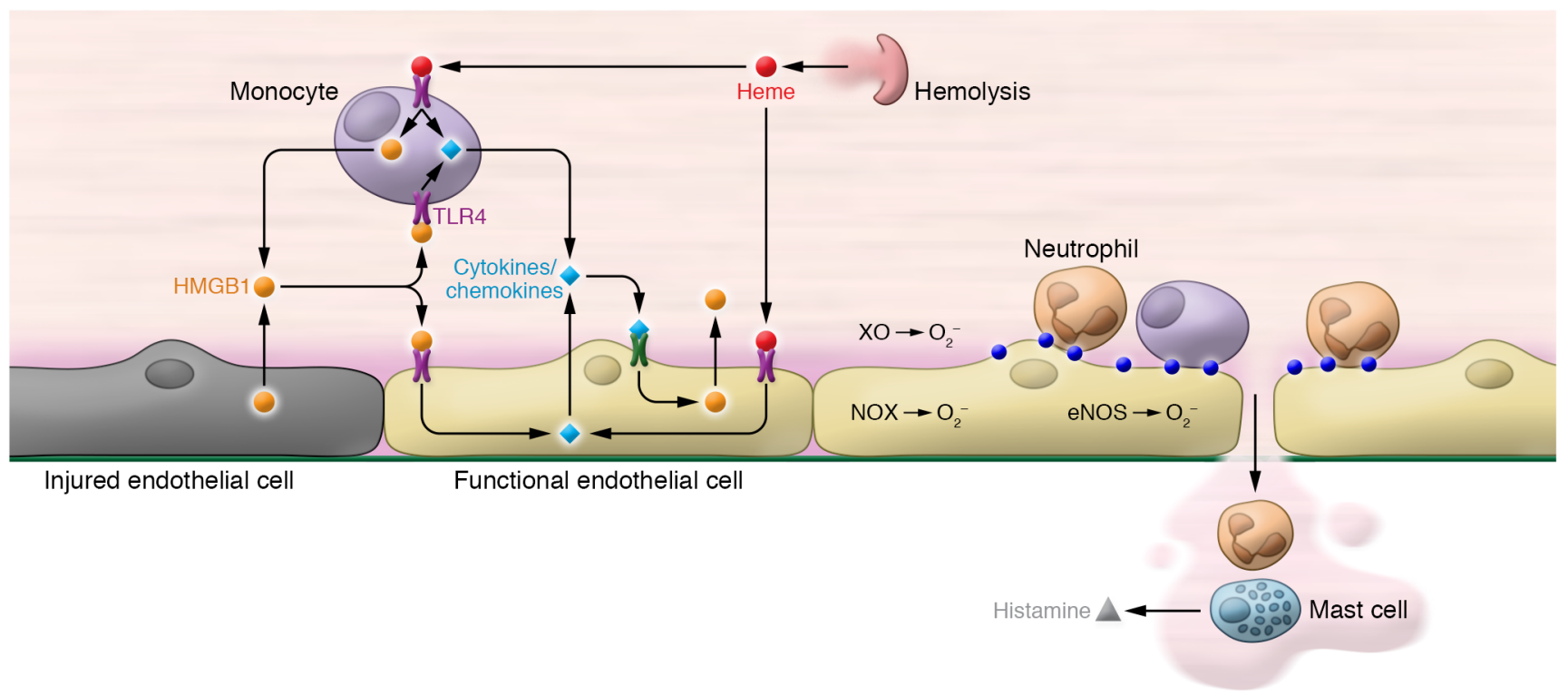

Figure 3. Key early features of I/R in the sickle context. (A) Compared with normal, baseline sickle vascular biology includes somewhat increased adhesion molecule expression, some baseline rolling of red cells and leukocytes on endothelium, and increased flow rate. Sickle vaso-occlusion is triggered by red cell and/or leukocyte adhesion in postcapillary venules, resulting in retrograde sickling and obstruction. Upon reperfusion, adhesion molecule expression and blood cell rolling and adhesion are far more prominent, the glycocalyx has thinned, and flow is notably hyperemic. (B) An expanded view of the reperfusion in $\mathbf{A}$, showing prominent early pathobiology of local I/R injury in SCA.

etc. In SCA, normality is overtaken by $\mathrm{I} / \mathrm{R}$, with prominent maladaptive consequences for the vascular wall (Figure 3).

\section{Oxidant generation}

In I/R generally, multiple sources of oxidant generation are extant and vary over time and among organs; most prominent are $\mathrm{XO}$, NADPH oxidase, cytochrome P450, and uncoupled eNOS $(6-8,49)$.

In sickle mice at baseline, $\mathrm{O}_{2}^{-}, \mathrm{H}_{2} \mathrm{O}_{2}$, and hydroxyl radical are generated in excess (17), and this worsens after $\mathrm{H} / \mathrm{R}$ provocation. Also at baseline, they exhibit abnormal XO on the endothelial surface (19) and eNOS uncoupling (57). Biochemical footprints of oxidative/nitrosative stress are apparent: tissue nitrotyrosine (19) and lipid peroxidation products (17) are present, and activities of heme oxygenase-1 (84) and Nrf2 (85) are increased. NADPH oxidase is found activated in phagocytic cells $(67,86), \mathrm{RBCs}(87)$, and endothelial cells (20), just as it is in arteriopathies generally (88). Indeed, in sickle mice, NADPH oxidase underlies cerebral vessel P-selectin exposure and occlusion (39).

Notably, the sickle milieu includes numerous NADPH oxidase activators, one of which is exposure of leukocytes and endothelial cells to sickle RBCs $(67,68)$. Also suspect is the anemic hyperemia, because abnormal shear stress can activate endothelial NADPH oxidase (89). In H/R-provoked sickle mice, the arterial endothelial oxidant level rises dramatically (20), and neurochemical perturbants 
increase further (90). Peculiarly, an increased inducible NO synthase (iNOS)/eNOS activity ratio is evident in sickle mouse kidney (34) and liver (23). In this regard, SCA mimics sepsis, in which increased iNOS activity coexists with a deficiency of eNOS activity (91).

\section{Glycocalyx thinning}

The endothelial thick glycocalyx separates endothelial surface and free flowing blood in all blood vessels $(92,93)$. In inflammatory contexts it is degraded (94), so we suspect this is present in SCA. This would be highly pathogenically relevant because glycocalyx integrity is required for multiple endothelial homeostatic functions, including proper mechanosensing of shear stress, repelling of adhesive blood cells, and several others.

\section{Endothelial hyperpermeability}

Proper regulation of endothelial barrier permeability controls accessibility of subendothelial space to water, solutes, and inflammatory cells. Barrier hyperpermeability is a hallmark feature of I/R pathophysiology $(8,95)$, and it is evident in sickle mice and patients (35). This is specifically relevant to brain and lung disease in SCA. H/R provocation of sickle mice activates mast cells (31) that can permeabilize monolayers of lung (96) and brain (97) endothelial cells. A variety of permeabilizing agents are abundant in SCA. High doses of heme, enough to cause cell and host death, can permeabilize pulmonary endothelial layers (96). Elevated TNF in sickle mice (27) and patients is relevant, as it not only permeabilizes endothelial and epithelial barriers but also impedes adaptive fluid reuptake.

\section{Endothelial adhesion biology}

In inflammatory syndromes, endothelial activation can derive from many perturbants, a plethora of which are documented in blood of sickle mice and patients (98). An example in H/R-provoked sickle mice is that activated monocytes produce TNF that activates venular endothelium to upregulate tissue factor (TF) and VCAM-1 (27). That SCA patients do have activated endothelium is evidenced by elevated levels of: endothelial-derived microparticles, some expressing TF and VCAM-1 (77); soluble adhesion molecules (98); and circulating endothelial cells (CECs) that are abnormally positive for TF, VCAM-1, ICAM-1, and E-selectin (P-selectin was not tested) (99-101). Sickle mice at baseline have correspondingly activated CECs and endothelium in situ (101).

$R B C$ adhesion. In vitro experiments have identified about 20 different mechanisms that can mediate sickle RBC adhesion to cultured endothelial cells in vitro (11), some shown in flow chambers (e.g., TNF-provoked adhesion via RBC $\alpha_{4} \beta_{1}$ and endothelial VCAM-1; ref. 102). However, only three mechanisms have been validated in sickle mice vivo under flow: P-selectin (103), $\alpha_{v} \beta_{3}$ (104), and ICAM-4/LW (105).

WBC adhesion. Two studies in the sickle mouse at baseline identified abnormal leukoadhesion with slowing of blood flow in cremaster and cerebral venules $(14,48)$. It was inhibited by P-selectin blockade but not by E-selectin blockade.

In another cremaster venular model, E-selectin was implicated in sickle mice challenged with $\operatorname{TNF}(15,106)$. In that model, adherent leukocytes can, if they engage E-selectin, activate $\alpha_{M} \beta_{2}$ integrin that then actually captures sickle RBCs, a heterocellular adhesion event that is mitigated by blockade of E-selectin. The devil being in the details, this E-selectin model $(15,106)$ employs a severe-phenotype sickle mouse (that at baseline has plasma TNF approximately $15 \mathrm{pg} / \mathrm{mL}$ and already exhibits substantial TNFdependent pathobiology; ref. 27) and injects it with an additional $500,000 \mathrm{pg}$ TNF, a dose that causes lethality within hours (106).

$I / R$ in general. In non-sickle $\mathrm{I} / \mathrm{R}$ models, leukoadhesion roles for various adhesion molecules have been identified $(6,8,107)$. In these models, P-selectin is virtually always implicated in leukocyte rolling, the first step in eventual capture, while E-selectin is implicated in some I/R models but not in others.

$H /$ R sickle mouse. The far greater leukoadhesion/emigration in cremaster venules of $\mathrm{H} / \mathrm{R}$-provoked sickle mice was mitigated by blockade of P-selectin but not of E-selectin (14). Similar data were obtained using cerebral venules (48). In dermal microvessels, leukoadhesion was limited by blockade of P-selectin, ICAM-1, and VCAM-1 (22). We note corresponding clinical trial data from SCA patients: P-selectin blockade using crizanlizumab exerted significant interventional and prophylactic efficacy, but E-selectin blockade with rivipansel failed to meet endpoints regarding vaso-occlusive severity $(74,75)$. Thus, in our opinion the available data most vividly highlight a role for P-selectin in adhesion biology of SCA and in sickle I/R. However, the vast complexity of adhesion biology argues that far more study, in physiologically relevant models, is required to truly understand functional adhesion biology in the sickle I/R context.

\section{Endothelial activation: coagulation}

Predictably, the endothelial-based, bidirectional activating linkage between inflammation and coagulation is evident in SCA as a hypercoagulable state (80) with abnormal activation of coagulation, fibrinolysis, and platelets. An example of its complexity is that the abnormal activation of platelets in SCA elevates plasma thrombospondin (108), which inhibits ADAMTS13 (109), resulting in abnormal high-molecular weight forms of von Willebrand factor (110) that mediate sickle RBC adhesion to endothelium (110).

\section{Endothelial vasoregulatory dysfunction}

It has been argued that in SCA the cause of eNOS dysfunction is consumption of NO by plasma oxyHbS (73). Our view is that this simply mimics some aspects of eNOS dysfunction but does not actually cause it (4). Actual eNOS uncoupling, on the other hand, is a hallmark feature of $\mathrm{I} / \mathrm{R}$ contexts $(6-8)$ and is present in sickle mice $(57,83,111)$ and patients $(58,59)$. The sickle milieu likely includes several abnormalities that are known causes of eNOS uncoupling: oxidation of tetrahydrobiopterin due to increased intracellular $\mathrm{O}_{2}^{-}$(112), inhibition from elevated asymmetric dimethyl arginine (113), and depletion of intracellular L-arginine by TNF-induced endothelial arginases $(114,115)$ and possibly by hypoxia-induced impairment of the L-arginine importer (116).

\section{Clinical consequences}

I/R undoubtedly contributes to many features of SCA; we suspect it is sufficient for some and necessary for many (Table 1).

\section{Local I/R injury to the brain}

The brain is the organ most vulnerable to I/R injury (8). In SCA, strokes of at least three types occur: small "silent" strokes that 
begin in childhood and occur lifelong, eventually in perhaps $50 \%$ of patients; hemorrhagic strokes in young adults; and cerebral artery clinical ischemic stroke affecting approximately $8 \%$ of children (117).

The concurrency of macrovascular hyperemia plus microvascular hypoperfusion in the SCA patient brain constitutes the perfusion paradox, revealing considerable shunting and oxygen demand/supply mismatching $(52,118-120)$. There is low vascular reserve, as the combination of endothelial dysfunction and anemic hyperemia heavily taxes adaptive capacity $(51,52)$. The regions that develop the silent strokes exhibit low perfusion, possibly from occlusion of penetrating venules (121), consistent with the postcapillary venular location of pathogenic blood cell adhesion in SCA. Thus, in sickle mice (50) and SCA patients $(51,52,118,119)$, parts of the brain are chronically hypoxic or on the borderline thereof.

Many aspects of $\mathrm{I} / \mathrm{R}$ pathophysiology likely participate in these events. Cerebrovascular P-selectin expression triggered by NADPH oxidase impedes cerebral microvascular flow $(39,48)$, and $H / R$ provocation triggers microinfarcts $(32,33)$. The brains of sickle mice and patients reveal abnormal blood-brain barrier hyperpermeability (35), a known feature of cerebral I/R models. Indeed, such hyperpermeability is implicated in lacunar strokes, stroke size, hemorrhagic transformation, and considerable cognitive disturbance $(122,123)$, thus paralleling SCA brain disease. It has been argued that, in general, normality of brain function requires normality of cerebrovascular endothelial function (124), highlighting the fundamental pathobiologic role of I/R-driven endothelial dysfunction in SCA.

\section{Local I/R injury to other organs}

The kidney's high osmolality, low $\mathrm{pH}$, and low $\mathrm{pO}_{2}$ are strong promoters of $\mathrm{HbS}$ polymerization, so it is not surprising that the organ exhibits high susceptibility to I/R injury (34). Thus, renal disease accounts for approximately $17 \%$ of mortality in SCA. Features of liver in SCA mimic those observed in experimental I/R models. While gut I/R has not been studied in the sickle context, we suspect its involvement because patients can manifest considerable abdominal pain during crises (and there can be celiac arteriopathy). I/R can contribute to nociceptive hypersensitivity. The bone marrow, frequently involved in the occlusive crises of SCA, would seem to be a setup for occurrence of $\mathrm{I} / \mathrm{R}$, given its low $\mathrm{pO}_{2}$ and sluggish flow (125); however, this has not been studied.

\section{Systematization of inflammation and arteriopathy}

The I/R-driven systematization of inflammation is the most prominent facet of I/R in SCA, as it engenders the template of endothelial vulnerability that profoundly contributes to all clinical pathology. We here focus on the arterial vasculopathy of SCA that occurs in brain, lung, bowel, penis, kidney, and spleen (126).

Although the amount of reviewable histopathology is suboptimal, a major feature is intimal hyperplasia, the arterial wall's universal response to endothelial inflammation (126). In human medicine, arterial disease emerges from the chronicity of such injury, so we believe that the I/R-driven systematization of inflammation subserves arteriopathic evolution in SCA. In particular, in parallel with their inciting roles in the paradigmatic arteriopathy, atherosclerosis, the abnormal activation of blood monocytes (127), and DAMP-driven TLR4 signaling $(26,28,128)$ likely play prominent roles in promoting SCA arteriopathy. Lesion locations, on the other hand, probably reflect added impact from various endothelial microenvironments (129).

Circle of Willis. Arteriopathy at the circle of Willis is strongly associated with childhood ischemic clinical stroke in SCA (117). Rather than one causing the other, however, it is suspected that each results from the anemic hyperemia of SCA. In support, experimental cerebral hyperperfusion was found to induce arteriopathy of the middle cerebral artery (130). The locational specificity could simply derive from abnormal shear stress patterns created by anemic hyperemia at cerebral artery divergences (131). The adverse effects of abnormal shear stress are many, but it can, e.g., induce endothelial NADPH oxidase activity (89).

Pulmonary arterial hypertension. Pulmonary arterial hypertension (PAH) surely is multifactorial in origin in SCA, just as it is in general medicine $(132,133)$. Adequate discussion of this is beyond the scope of this Review. Yet, in SCA, I/R-driven systematization of inflammation comprises a "perfect storm" that includes a great many relevant perturbants implicated in the general PAH medicine literature. Some of these are anemic hyperemia (134), DAMP signaling (135), growth factors, vasoregulators, coagulation/platelet activation, recurrent hypoxia from sleep apnea, and arterial glycocalyx degradation PAH (136). And, unique to the pulmonary artery, we hypothesize a meaningful role for endothelial injury that results from chronic endothelial molestation by the sickled RBCs in venous blood, as illustrated by in vitro experiments $(68,69)$.

\section{Remote organ injury}

Local I/R injury can be complicated by disease developing in a distant organ, an inflammatory acute lung syndrome being the most common example (8). Lung susceptibility derives from its unique features: constitutive endothelial P-selectin expression in pulmonary capillaries, enormous baseline marginated leukocyte pool, capillaries in series (137). In SCA, features of the acute chest syndrome perfectly match examples of remote organ injury in general medicine (36).

\section{Implications for therapeutics}

The complex systems biology of the sickle I/R state involves a multitude of theoretical targets and, therefore, possible therapeutic approaches. The section above on "Therapeutic corroboration" describes nearly two dozen concrete examples of drugs that improve microvascular blood flow in $\mathrm{H} / \mathrm{R}$-provoked sickle mice. Although this implies that there may be many viable therapeutic approaches to sickle I/R, in reality each discrete step in Figure 1 comprises its own extraordinarily complex network.

Thus, it is probably naive to believe that sickle I/R can be effectively targeted with a single drug. And, of course, data from the sickle mouse may not be predictive of the SCA human. For example, the cardiac output of the mouse is 6-fold (by weight) greater than that of the human. Nonetheless, we suggest that this vastly intricate systems biology has two points of I/R vulnerability (we do not discuss targeting HbS polymerization herein).

\section{Targetable vulnerabilities}

One point of vulnerability may be the actual initiation step of $\mathrm{I} / \mathrm{R}$ pathobiology, i.e., before it has arborized and reached mature 
complexity. Targeting early events at this specific step with multiple drugs may be possible. We previously suggested an example combining three drugs already deployed in general medicine: allopurinol to inhibit XO (17), sulfasalazine to inhibit NF- $\mathrm{KB}$ (20), and etanercept to block TNF (27). Each individually improves microvascular flow in H/R-provoked sickle mice. We have elsewhere emphasized that proof of biological efficacy can be obtained on such drugs using very few subjects if tested longitudinally - we advise use of this strategy for efficacy screening. We also do believe that statins are logical for SCA. Their pleiotropic, endothelial-sparing effects are evident in non-sickle I/R models (138), in $\mathrm{H} / \mathrm{R}$-provoked sickle mice $(18,139)$, and perhaps in sickle patients (140). In fact, they are reported to exert tissue conditioning effects protective against subsequent I/R (141).

The second point of vulnerability lies in the central role that I/R-driven blood cell adhesion to endothelium plays in the perpetual cycling between occlusion and adhesion. So, targeting this adhesion is an indirect way to limit HbS polymerization. As articulated herein, our view is that fairly robust data argue for blocking P-selectin using crizanlizumab $(74)$ or a heparinoid $(142,143)$.

\section{Conclusion}

The pathophysiology of sickle cell anemia involves a unique form of $\mathrm{I} / \mathrm{R}$ pathobiology that drives the robust inflammatory state, notable for its cyclicity, intensity, instability, complexity, and perpetuity. Certain specific clinical complications of SCA can be attributed, in large part, to local I/R injury (e.g., cerebrovascular disease) or I/R remote organ injury (e.g., acute chest syndrome) or I/R systematization of inflammation (e.g., arteriopathy). In the broad view, it is likely that the inflammatory systematization, via the template of endothelial dysfunction and vulnerability it establishes, contributes to all clinical disease in SCA.

Encouragingly, experimental studies have identified a number of strategies and multiple specific drugs that improve microvascular blood flow in sickle mice provoked via exposure to hypoxia/ reoxygenation, a maneuver that induces an acute, bona fide $I / R$ state in such mice. Unfortunately, a persistent stenosis in the bench-to-bedside translational pipeline has prevented promising approaches targeting I/R from reaching clinical investigation despite our demonstration long ago that solid data confirmatory of in vivo human biological efficacy can be obtained by longitudinal study of as few as three SCA patients (53). We hope this Review will help persuade the sickle research community that such I/Rtargeting approaches are worth testing in the clinic.

\section{Acknowledgments}

The authors thank all the trainees and colleagues from our laboratories who participated in the experimental work cited here. The authors' work has been supported by multiple NIH grants since 1978, most recently by HL55552 and HL114567.

Address correspondence to: Robert P. Hebbel, MMC 480, Hematology, 420 Delaware St. S.E., Minneapolis, Minnesota 55455, USA. Phone: 612.626.2446; Email: hebbe001@umn.edu.
1. Ferrone FA. Polymerization and sickle cell disease: a molecular view. Microcirculation. 2004;11(2):115-128.

2. Hebbel RP, Morgan WT, Eaton JW, Hedlund BE Accelerated autoxidation and heme loss due to instability of sickle hemoglobin. Proc Natl Acad Sci U S A. 1988;85(1):237-241.

3. Browne P, Shalev O, Hebbel RP. The molecular pathobiology of cell membrane iron: the sickle red cell as a model. Free Radic Biol Med. 1998;24(6):1040-1048.

4. Hebbel RP. Reconstructing sickle cell disease: a data-based analysis of the "hyperhemolysis paradigm" for pulmonary hypertension from the perspective of evidence-based medicine. Am J Hematol. 2011;86(2):123-154.

5. Embury SH. The not-so-simple process of sickle cell vasoocclusion. Microcirculation. 2004;11(2):101-113.

6. Granger DN. Ischemia-reperfusion: mechanisms of microvascular dysfunction and the influence of risk factors for cardiovascular disease. Microcirculation. 1999;6(3):167-178.

7. Granger DN, Kvietys PR. Reperfusion injury and reactive oxygen species: the evolution of a concept. Redox Biol. 2015;6:524-551.

8. Kalogeris T, Baines CP, Krenz M, Korthuis RJ. Ischemia/reperfusion. Compr Physiol. 2016;7(1):113-170.

9. Christoph GW, Hofrichter J, Eaton WA. Understanding the shape of sickled red cells. Biophys J. 2005;88(2):1371-1376.

10. Hebbel RP, Yamada O, Moldow CF, Jacob HS, White JG, Eaton JW. Abnormal adherence of sickle erythrocytes to cultured vascular endothelium: possible mechanism for microvascular occlusion in sickle cell disease. J Clin Invest. 1980;65(1):154-160.

11. Hebbel RP. Perspectives series: cell adhesion in vascular biology. Adhesive interactions of sickle erythrocytes with endothelium. J Clin Invest. 1997;99(11):2561-2564.

12. Kaul DK, Fabry ME, Nagel RL. Microvascular sites and characteristics of sickle cell adhesion to vascular endothelium in shear flow conditions: pathophysiological implications. Proc Natl Acad Sci U S A. 1989;86(9):3356-3360.

13. Kaul DK, Fabry ME, Costantini F, Rubin EM, Nagel RL. In vivo demonstration of red cell-endothelial interaction, sickling and altered microvascular response to oxygen in the sickle transgenic mouse. JClin Invest. 1995;96(6):2845-2853.

14. Kaul DK, Hebbel RP. Hypoxia/reoxygenation causes inflammatory response in transgenic sickle mice but not in normal mice. JClin Invest. 2000;106(3):411-420.

15. Zhang D, Xu C, Manwani D, Frenette PS. Neutrophils, platelets, and inflammatory pathways at the nexus of sickle cell disease pathophysiology. Blood. 2016;127(7):801-809.

16. Polanowska-Grabowska R, et al. P-selectinmediated platelet-neutrophil aggregate formation activates neutrophils in mouse and human sickle cell disease. Arterioscler Thromb Vasc Biol. 2010;30(12):2392-2399.

17. Osarogiagbon UR, Choong S, Belcher JD, Vercellotti GM, Paller MS, Hebbel RP. Reperfusion injury pathophysiology in sickle transgenic mice.
Blood. 2000;96(1):314-320.

18. Solovey A, et al. Endothelial cell expression of tissue factor in sickle mice is augmented by hypoxia/ reoxygenation and inhibited by lovastatin. Blood. 2004;104(3):840-846.

19. Aslan M, Freeman BA. Redox-dependent impairment of vascular function in sickle cell disease. Free Radic Biol Med. 2007;43(11):1469-1483.

20. Kaul DK, Liu XD, Choong S, Belcher JD, Vercellotti GM, Hebbel RP. Anti-inflammatory therapy ameliorates leukocyte adhesion and microvascular flow abnormalities in transgenic sickle mice. Am J Physiol Heart Circ Physiol. 2004;287(1):H293-H301.

21. Belcher JD, et al. Transgenic sickle mice have vascular inflammation. Blood. 2003;101(10):3953-3959.

22. Belcher JD, et al. Critical role of endothelial cell activation in hypoxia-induced vasoocclusion in transgenic sickle mice. Am J Physiol Heart Circ Physiol. 2005;288(6):H2715-H2725.

23. Siciliano A, et al. Abnormal modulation of cell protective systems in response to ischemic/ reperfusion injury is important in the development of mouse sickle cell hepatopathy. Haematologica. 2011;96(1):24-32.

24. Kollander R, Solovey A, Milbauer LC, Abdulla F, Kelm RJ, Hebbel RP. Nuclear factor-kappa B (NFKB) component p50 in blood mononuclear cells regulates endothelial tissue factor expression in sickle transgenic mice: implications for the coagulopathy of sickle cell disease. Transl Res. 2010;155(4):170-177.

25. Vercellotti GM, et al. Critical role of C5a in sickle 
cell disease. Am J Hematol. 2019;94(3):327-337.

26. Belcher JD, et al. Heme triggers TLR4 signaling leading to endothelial cell activation and vaso-occlusion in murine sickle cell disease. Blood. 2014;123(3):377-390.

27. Solovey A, et al. A monocyte-TNF-endothelial activation axis in sickle transgenic mice: therapeutic benefit from TNF blockade. Am J Hematol. 2017;92(11):1119-1130.

28. Xu H, et al. Sickle cell disease increases high mobility group box 1: a novel mechanism of inflammation. Blood. 2014;124(26):3978-3981.

29. Ballas SK, Marcolina MJ. Hyperhemolysis during the evolution of uncomplicated acute painful episodes in patients with sickle cell anemia. Transfusion. 2006;46(1):105-110.

30. Belcher JD, Marker PH, Weber JP, Hebbel RP, Vercellotti GM. Activated monocytes in sickle cell disease: potential role in the activation of vascular endothelium and vaso-occlusion. Blood. 2000;96(7):2451-2459.

31. Vincent $\mathrm{L}$, et al. Mast cell activation contributes to sickle cell pathobiology and pain in mice. Blood. 2013;122(11):1853-1862.

32. Sun YY, et al. Sickle mice are sensitive to hypoxia/ ischemia-induced stroke but respond to tissuetype plasminogen activator treatment. Stroke. 2017;48(12):3347-3355.

33. Hyacinth HI, Sugihara CL, Spencer TL, Archer DR, Shih AY. Higher prevalence of spontaneous cerebral vasculopathy and cerebral infarcts in a mouse model of sickle cell disease. J Cereb Blood Flow Metab. 2019;39(2):342-351.

34. Nath KA, Hebbel RP. Sickle cell disease: renal manifestations and mechanisms. Nat Rev Nephrol. 2015;11(3):161-171.

35. Manci EA, Hillery CA, Bodian CA, Zhang ZG, Lutty GA, Coller BS. Pathology of Berkeley sickle cell mice: similarities and differences with human sickle cell disease. Blood. 2006;107(4):1651-1658.

36. Hebbel RP. Ischemia-reperfusion injury in sickle cell anemia: relationship to acute chest syndrome, endothelial dysfunction, arterial vasculopathy, and inflammatory pain. Hematol Oncol Clin North Am. 2014;28(2):181-198.

37. Telen MJ, Malik P, Vercellotti GM. Therapeutic strategies for sickle cell disease: towards a multi-agent approach. Nat Rev Drug Discov. 2019;18(2):139-158.

38. Mahaseth $\mathrm{H}$, et al. Polynitroxyl albumin inhibits inflammation and vasoocclusion in transgenic sickle mice. J Lab Clin Med. 2005;145(4):204-211.

39. Wood KC, Hebbel RP, Granger DN. Endothelial cell NADPH oxidase mediates the cerebral microvascular dysfunction in sickle cell transgenic mice. FASEB J. 2005;19(8):989-991.

40. Kaul DK, et al. Robust vascular protective effect of hydroxamic acid derivatives in a sickle mouse model of inflammation. Microcirculation. 2006;13(6):489-497.

41. Hebbel RP, et al. The HDAC inhibitors trichostatin A and suberoylanilide hydroxamic acid exhibit multiple modalities of benefit for the vascular pathobiology of sickle transgenic mice. Blood. 2010;115(12):2483-2490.

42. Belcher JD, et al. Haptoglobin and hemopexin inhibit vaso-occlusion and inflammation in murine sickle cell disease: role of heme oxygenase-1 induction. PLoS One. 2018;13(4):e0196455.

43. Belcher JD, et al. Heme oxygenase-1 gene delivery by Sleeping Beauty inhibits vascular stasis in a murine model of sickle cell disease. JMol Med. 2010;88(7):665-675.

44. Belcher JD, et al. MP4CO, a pegylated hemoglobin saturated with carbon monoxide, is a modulator of HO-1, inflammation, and vaso-occlusion in transgenic sickle mice. Blood. 2013;122(15):2757-2764

45. Belcher JD, et al. Oral carbon monoxide therapy in murine sickle cell disease: beneficial effects on vaso-occlusion, inflammation and anemia. PLoS One. 2018;13(10):e0205194.

46. Embury SH, et al. The contribution of endothelial cell P-selectin to the microvascular flow of mouse sickle erythrocytes in vivo. Blood. 2004;104(10):3378-3385.

47. Belcher JD, et al. The fucosylation inhibitor, 2-fluorofucose, inhibits vaso-occlusion, leukocyte-endothelium interactions and NF- $\mathrm{kB}$ activation in transgenic sickle mice. PLoS One. 2015;10(2):e0117772.

48. Wood KC, Hebbel RP, Granger DN. Endothelial cell P-selectin mediates a proinflammatory and prothrombogenic phenotype in cerebral venules of sickle cell transgenic mice. Am J Physiol Heart Circ Physiol. 2004;286(5):H1608-H1614.

49. Eltzschig HK, Eckle T. Ischemia and reperfusion - from mechanism to translation. Nat Med. 2011;17(11):1391-1401.

50. Cahill LS, et al. Functional and anatomical evidence of cerebral tissue hypoxia in young sickle cell anemia mice. J Cereb Blood Flow Metab. 2017;37(3):994-1005.

51. Prohovnik I, Hurlet-Jensen A, Adams R, De Vivo D, Pavlakis SG. Hemodynamic etiology of elevated flow velocity and stroke in sickle-cell disease. JCereb Blood Flow Metab. 2009;29(4):803-810.

52. Wood JC. Brain $\mathrm{O}_{2}$ reserve in sickle cell disease. Blood. 2019;133(22):2356-2358.

53. Hebbel RP, Elion J, Kutlar A. The missing middle of sickle therapeutics: multi-agent therapy, targeting risk, using biomarkers. Am J Hematol. 2018;93(12):1439-1443.

54. Matte A, et al. Resolution of sickle cell diseaseassociated inflammation and tissue damage with 17R-resolvin D1. Blood. 2019;133(3):252-265.

55. Schaefer L. Complexity of danger: the diverse nature of damage-associated molecular patterns. J Biol Chem. 2014;289(51):35237-35245.

56. Goodall KJ, Poon IK, Phipps S, Hulett MD. Soluble heparan sulfate fragments generated by heparanase trigger the release of pro-inflammatory cytokines through TLR-4. PLoS One. 2014;9(10):e109596.

57. Hsu LL, et al. Hemolysis in sickle cell mice causes pulmonary hypertension due to global impairment in nitric oxide bioavailability. Blood. 2007;109(7):3088-3098.

58. Gladwin MT, et al. Divergent nitric oxide bioavailability in men and women with sickle cell disease. Circulation. 2003;107(2):271-278.

59. de Montalembert M, Aggoun Y, Niakate A, Szezepanski I, Bonnet D. Endothelial-dependent vasodilation is impaired in children with sickle cell disease. Haematologica. 2007;92(12):1709-1710.
60. Liu R, Evgenov OV, Ichinose F. NOS3 deficiency augments hypoxic pulmonary vasoconstriction and enhances systemic oxygenation during one-lung ventilation in mice. J Appl Physiol. 2005;98(2):748-752.

61. Rosen CL, et al. Obstructive sleep apnea and sickle cell anemia. Pediatrics. 2014;134(2):273-281.

62. Dutra FF, et al. Hemolysis-induced lethality involves inflammasome activation by heme. Proc Natl Acad Sci U S A. 2014;111(39):E4110-E4118.

63. Erdei J, et al. Induction of NLRP3 inflammasome activation by heme in human endothelial cells. Oxid Med Cell Longev. 2018;2018:4310816.

64. Vogel S, et al. The platelet NLRP3 inflammasome is upregulated in sickle cell disease via HMGB1/ TLR4 and Bruton tyrosine kinase. Blood Adv. 2018;2(20):2672-2680.

65. van Beers EJ, et al. Iron, inflammation, and early death in adults with sickle cell disease. Circ Res. 2015;116(2):298-306.

66. Pitanga TN, et al. Sickle red cells as danger signals on proinflammatory gene expression, leukotriene $\mathrm{B} 4$ and interleukin- 1 beta production in peripheral blood mononuclear cell. Cytokine. 2016;83:75-84.

67. Hofstra TC, Kalra VK, Meiselman HJ, Coates TD. Sickle erythrocytes adhere to polymorphonuclear neutrophils and activate the neutrophil respiratory burst. Blood. 1996;87(10):4440-4447.

68. Sultana C, Shen Y, Rattan V, Johnson C, Kalra VK. Interaction of sickle erythrocytes with endothelial cells in the presence of endothelial cell conditioned medium induces oxidant stress leading to transendothelial migration of monocytes. Blood. 1998;92(10):3924-3935.

69. Phelan M, Perrine SP, Brauer M, Faller DV. Sickle erythrocytes, after sickling, regulate the expression of the endothelin-1 gene and protein in human endothelial cells in culture. JClin Invest. 1995;96(2):1145-1151.

70. Kangelaris KN, et al. The association between a Darc gene polymorphism and clinical outcomes in African American patients with acute lung injury. Chest. 2012;141(5):1160-1169.

71. Ferwerda B, et al. Functional consequences of toll-like receptor 4 polymorphisms. Mol Med. 2008;14(5-6):346-352.

72. Charrin E, et al. Moderate exercise training decreases inflammation in transgenic sickle cell mice. Blood Cells Mol Dis. 2018;69:45-52.

73. Kato GJ, Steinberg MH, Gladwin MT. Intravascular hemolysis and the pathophysiology of sickle cell disease. J Clin Invest. 2017;127(3):750-760.

74. Ataga KI, et al. Crizanlizumab for the prevention of pain crises in sickle cell disease. $N$ Engl J Med. 2017;376(5):429-439.

75. Vichinsky E, et al. A phase 3 randomized trial of voxeletor in sickle cell disease. $N$ Engl J Med. 2019;381(6):509-519.

76. Reiter CD, et al. Cell-free hemoglobin limits nitric oxide bioavailability in sickle-cell disease. Nat Med. 2002;8(12):1383-1389.

77. Hebbel RP, Key NS. Microparticles in sickle cell anaemia: promise and pitfalls. Br J Haematol. 2016;174(1):16-29.

78. Camus SM, et al. Erythrocyte microparticles can induce kidney vaso-occlusions in a murine model of sickle cell disease. Blood. 
2012;120(25):5050-5058.

79. Camus SM, et al. Circulating cell membrane microparticles transfer heme to endothelial cells and trigger vasoocclusions in sickle cell disease. Blood. 2015;125(24):3805-3814.

80. Faes C, Sparkenbaugh EM, Pawlinski R. Hypercoagulable state in sickle cell disease. Clin Hemorheol Microcirc. 2018;68(2-3):301-318.

81. Belcher JD, et al. Low-density lipoprotein susceptibility to oxidation and cytotoxicity to endothelium in sickle cell anemia. J Lab Clin Med. 1999;133(6):605-612.

82. Balla G, Jacob HS, Eaton JW, Belcher JD, Vercellotti GM. Hemin: a possible physiological mediator of low density lipoprotein oxidation and endothelial injury. Arterioscler Thromb. 1991;11(6):1700-1711.

83. Ou J, et al. L-4F, an apolipoprotein A-1 mimetic, dramatically improves vasodilation in hypercholesterolemia and sickle cell disease. Circulation. 2003;107(18):2337-2341.

84. Bains SK, Foresti R, Howard J, Atwal S, Green CJ, Motterlini R. Human sickle cell blood modulates endothelial heme oxygenase activity: effects on vascular adhesion and reactivity. Arterioscler Thromb Vasc Biol. 2010;30(2):305-312.

85. Keleku-Lukwete N, et al. Nrf2 activation in myeloid cells and endothelial cells differentially mitigates sickle cell disease pathology in mice. Blood Adv. 2019;3(8):1285-1297.

86. Marçal LE, et al. Up-regulation of NADPH oxidase components and increased production of interferon- $\gamma$ by leukocytes from sickle cell disease patients. Am J Hematol. 2008;83(1):41-45.

87. MacKinney A, Woska E, Spasojevic I, BatinicHaberle I, Zennadi R. Disrupting the vicious cycle created by NOX activation in sickle erythrocytes exposed to hypoxia/reoxygenation prevents adhesion and vasoocclusion. Redox Biol. 2019;25:101097.

88. Drummond GR, Selemidis S, Griendling KK, Sobey CG. Combating oxidative stress in vascular disease: NADPH oxidases as therapeutic targets. Nat Rev Drug Discov. 2011;10(6):453-471.

89. Hwang J, et al. Pulsatile versus oscillatory shear stress regulates NADPH oxidase subunit expression: implication for native LDL oxidation. Circ Res. 2003;93(12):1225-1232.

90. Cui MH, et al. Brain neurochemical and hemodynamic findings in the NY1DD mouse model of mild sickle cell disease. NMR Biomed. 2017;30(5):e3692.

91. Aird WC. The role of the endothelium in severe sepsis and multiple organ dysfunction syndrome. Blood. 2003;101(10):3765-3777.

92. Reitsma S, Slaaf DW, Vink H, van Zandvoort MA, oude Egbrink MG. The endothelial glycocalyx: composition, functions, and visualization. Pflugers Arch. 2007;454(3):345-359.

93. Weinbaum S, Tarbell JM, Damiano ER. The structure and function of the endothelial glycocalyx layer. Annu Rev Biomed Eng. 2007;9:121-167.

94. Becker BF, Jacob M, Leipert S, Salmon AH, Chappell D. Degradation of the endothelial glycocalyx in clinical settings: searching for the sheddases. Br JClin Pharmacol. 2015;80(3):389-402.

95. Kumar P, Shen Q, Pivetti CD, Lee ES, Wu MH, Yuan SY. Molecular mechanisms of endothelial hyperpermeability: implications in inflammation. Expert Rev Mol Med. 2009;11:e19.

96. Singla S, Sysol JR, Dille B, Jones N, Chen J, Machado RF. Hemin causes lung microvascular endothelial barrier dysfunction by necroptotic cell death. Am J Respir Cell Mol Biol. 2017;57(3):307-314.

97. Tran H, et al. Mast cells induce blood brain barrier damage in SCD by causing endoplasmic reticulum stress in the endothelium. Front Cell Neurosci. 2019;13:56.

98. Hoppe CC. Inflammatory mediators of endothelial injury in sickle cell disease. Hematol Oncol Clin North Am. 2014;28(2):265-286.

99. Solovey A, Lin Y, Browne P, Choong S, Wayner E, Hebbel RP. Circulating activated endothelial cells in sickle cell anemia. $N$ Engl JMed. 1997;337(22):1584-1590.

100.Solovey A, Gui L, Key NS, Hebbel RP. Tissue factor expression by endothelial cells in sickle cell anemia. JClin Invest. 1998;101(9):1899-1904.

101. Solovey AA, Solovey AN, Harkness J, Hebbel RP. Modulation of endothelial cell activation in sickle cell disease: a pilot study. Blood. 2001;97(7):1937-1941.

102. Swerlick RA, Eckman JR, Kumar A, Jeitler M, Wick TM. Alpha 4 beta 1-integrin expression on sickle reticulocytes: vascular cell adhesion molecule-1-dependent binding to endothelium. Blood 1993;82(6):1891-1899.

103. Matsui NM, Varki A, Embury SH. Heparin inhibits the flow adhesion of sickle red blood cells to P-selectin. Blood. 2002;100(10):3790-3796.

104.Finnegan EM, Barabino GA, Liu XD, Chang HY, Jonczyk A, Kaul DK. Small-molecule cyclic alpha $\mathrm{V}$ beta 3 antagonists inhibit sickle red cell adhesion to vascular endothelium and vasoocclusion. Am J Physiol Heart Circ Physiol. 2007;293(2):H1038-H1045

105.Zennadi R, et al. Epinephrine-induced activation of LW-mediated sickle cell adhesion and vasoocclusion in vivo. Blood. 2007;110(7):2708-2717.

106. Hidalgo A, Chang J, Jang JE, Peired AJ, Chiang EY, Frenette PS. Heterotypic interactions enabled by polarized neutrophil microdomains mediate thromboinflammatory injury. Nat Med. 2009;15(4):384-391.

107. Thiagarajan RR, Winn RK, Harlan JM. The role of leukocyte and endothelial adhesion molecules in ischemia-reperfusion injury. Thromb Haemost. 1997;78(1):310-314.

108. Solovey A, Gui L, Ramakrishnan S, Steinberg MH, Hebbel RP. Sickle cell anemia as a possible state of enhanced anti-apoptotic tone: survival effect of vascular endothelial growth factor on circulating and unanchored endothelial cells. Blood.1999;93(11):3824-3830.

109. Novelli EM, et al. Thrombospondin-1 inhibits ADAMTS13 activity in sickle cell disease. Haematologica. 2013;98(11):e132-e134.

110.Wick TM, Moake JL, Udden MM, Eskin SG, Sears DA, McIntire LV. Unusually large von Willebrand factor multimers increase adhesion of sickle erythrocytes to human endothelial cells under controlled flow. J Clin Invest. 1987;80(3):905-910.

111. Kaul DK, Liu XD, Fabry ME, Nagel RL. Impaired nitric oxide-mediated vasodilation in transgenic sickle mouse. Am J Physiol Heart Circ Physiol. 2000;278(6):H1799-H1806.
112. Crabtree MJ, et al. Quantitative regulation of intracellular endothelial nitric-oxide synthase (eNOS) coupling by both tetrahydrobiopterineNOS stoichiometry and biopterin redox status: insights from cells with tet-regulated GTP cyclohydrolase I expression. J Biol Chem. 2009;284(2):1136-1144.

113. Kato GJ, Wang Z, Machado RF, Blackwelder WC, Taylor JG, Hazen SL. Endogenous nitric oxide synthase inhibitors in sickle cell disease: abnormal levels and correlations with pulmonary hypertension, desaturation, haemolysis, organ dysfunction and death. Br J Haematol. 2009;145(4):506-513.

114. Gao X, et al. TNF- $\alpha$ contributes to endothelial dysfunction by upregulating arginase in ischemia/reperfusion injury. Arterioscler Thromb Vasc Biol. 2007;27(6):1269-1275.

115. Zhang C, Wu J, Xu X, Potter BJ, Gao X. Direct relationship between levels of TNF- $\alpha$ expression and endothelial dysfunction in reperfusion injury. Basic Res Cardiol. 2010;105(4):453-464.

116. Block ER, Herrera H, Couch M. Hypoxia inhibits L-arginine uptake by pulmonary artery endothelial cells. Am JPhysiol. 1995;269(5 pt 1):L574-L580.

117. Jordan LC, DeBaun MR. Cerebral hemodynamic assessment and neuroimaging across the lifespan in sickle cell disease. JCereb Blood Flow Metab. 2018;38(9):1438-1448.

118. Chai $Y$, et al. White matter has impaired resting oxygen delivery in sickle cell patients. Am J Hematol. 2019;94(4):467-474.

119. Ford AL, et al. Silent infarcts in sickle cell disease occur in the border zone region and are associated with low cerebral blood flow. Blood. 2018;132(16):1714-1723.

120. Detterich JA, et al. Sickle cell microvascular paradox-oxygen supply-demand mismatch. Am J Hematol. 2019;94(6):678-688.

121. Hartmann DA, Hyacinth HI, Liao FF, Shih AY. Does pathology of small venules contribute to cerebral microinfarcts and dementia? J Neurochem. 2018;144(5):517-526.

122. Wardlaw JM, et al. Lacunar stroke is associated with diffuse blood-brain barrier dysfunction. Ann Neurol. 2009;65(2):194-202.

123. Schoknecht K, David Y, Heinemann U. The blood-brain barrier-gatekeeper to neuronal homeostasis: clinical implications in the setting of stroke. Semin Cell Dev Biol. 2015;38:35-42.

124. Rajani RM, et al. Reversal of endothelial dysfunction reduces white matter vulnerability in cerebral small vessel disease in rats. Sci Transl Med. 2018;10(448):eaam9507.

125. Spencer JA, et al. Direct measurement of local oxygen concentration in the bone marrow of live animals. Nature. 2014;508(7495):269-273.

126. Hebbel RP, Osarogiagbon R, Kaul D. The endothelial biology of sickle cell disease: inflammation and a chronic vasculopathy. Microcirculation. 2004;11(2):129-151.

127. Pamukcu B, Lip GY, Devitt A, Griffiths H, Shantsila E. The role of monocytes in atherosclerotic coronary artery disease. Ann Med. 2010;42(6):394-403.

128. Frantz S, Ertl G, Bauersachs J. Mechanisms of disease: Toll-like receptors in cardiovascular disease. Nat Clin Pract Cardiovasc Med. 2007;4(8):444-454. 
129. Aird WC. Spatial and temporal dynamics of the endothelium. J Thromb Haemost. 2005;3(7):1392-1406.

130. Onetti $Y$, et al. Middle cerebral artery remodeling following transient brain ischemia is linked to early postischemic hyperemia: a target of uric acid treatment. Am J Physiol Heart Circ Physiol. 2015;308(8):H862-H874.

131. Davies PF, Civelek M, Fang Y, Fleming I. The atherosusceptible endothelium: endothelial phenotypes in complex haemodynamic shear stress regions in vivo. Cardiovasc Res. 2013;99(2):315-327.

132. Schermuly RT, Ghofrani HA, Wilkins MR, Grimminger F. Mechanisms of disease: pulmonary arterial hypertension. Nat Rev Cardiol. 2011;8(8):443-455.

133. Rabinovitch M. Molecular pathogenesis of pulmonary arterial hypertension. JClin Invest. 2012;122(12):4306-4313
134. Minatsuki S, et al. Murine model of pulmonary artery overflow vasculopathy revealed macrophage accumulation in the lung. Int Heart J. 2019;60(2):451-456.

135. Bauer EM, et al. High mobility group box 1 contributes to the pathogenesis of experimental pulmonary hypertension via activation of Toll-like receptor 4. Mol Med. 2013;18:1509-1518.

136. Guo J, Yang ZC, Liu Y. Attenuating pulmonary hypertension by protecting the integrity of glycocalyx in rats model of pulmonary artery hypertension. Inflammation. 2019;42(6):1951-1956.

137. Reutershan J, Ley K. Bench-to-bedside review: acute respiratory distress syndrome - how neutrophils migrate into the lung. Crit Care. 2004;8(6):453-461.

138. Abdul Rahman MN, Chetter IC. Statins and ischaemia reperfusion injury: a molecular biological review. Curr Vasc Pharmacol. 2010;8(6):831-835. 139. Zahr RS, Chappa P, Yin H, Brown LA, Ataga KI,
Archer DR. Renal protection by atorvastatin in a murine model of sickle cell nephropathy. $\mathrm{Br} \mathrm{J}$ Haematol. 2018;181(1):111-121.

140. Hoppe C, Jacob E, Styles L, Kuypers F, Larkin S, Vichinsky E. Simvastatin reduces vaso-occlusive pain in sickle cell anaemia: a pilot efficacy trial. Br J Haematol. 2017;177(4):620-629.

141. Tuuminen R, et al. Donor simvastatin treatment prevents ischemia-reperfusion and acute kidney injury by preserving microvascular barrier function. Am J Transplant. 2013;13(8):2019-2034.

142. Telen MJ, et al. Sevuparin binds to multiple adhesive ligands and reduces sickle red blood cell-induced vaso-occlusion. Br J Haematol. 2016;175(5):935-948.

143. Kutlar A, et al. A potent oral P-selectin blocking agent improves microcirculatory blood flow and a marker of endothelial cell injury in patients with sickle cell disease. Am J Hematol. 2012;87(5):536-539. 